\title{
PROSPECTS FOR THE USE OF ALCOHOL INFUSIONS IN ALCOHOLIC BEVERAGE TECHNOLOGIES FOR RESTAURANTS
}

\author{
Kuzmin O. V., Rudyi V. V.
}

\section{INTRODUCTION}

Nowadays, the use of vegetable raw materials in the technology of alcoholic beverages is being increasingly used in restaurants ${ }^{1}$. Due to the content of antioxidants (vitamins, flavonoids, tannins, organic acids, etc.), plant raw materials are capable of exhibiting antioxidant properties $^{2,3,4}$. Antioxidants include substances that can inhibit the radical oxidation of organic and macromolecular compounds. Antioxidants are able to reduce the output of oxidation products ${ }^{6}$ : hydroperoxides, alcohols, aldehydes, ketones, fatty acids and the like.

A wide range of alcoholic beverages is based on the use of a variety of vegetable raw materials. Semi-finished products (aromatic alcohols, infusions, alcoholic juices, fruit drinks, etc.) are prepared from vegetable raw materials. On the one hand, the use of vegetable raw materials allows you to shape the taste, aroma, color of alcoholic beverages. On

1 Kuzmin O., Kovalchuk Y., Velychko V., Romanchenko N. Improvement technologies of aqueous-alcoholic infusions for the production of syrups. Ukrainian Journal of Food Science. 2016.4 (2). pp. 258-275.

2 Breiter T., Laue C. Kressel G., Gröll S., Hahn A. Bioavailability and antioxidant potential of rooibos flavonoids in humans following the consumption of different rooibos formulations. Food Chemistry. 2011.128 (215) pp. 338-347.

${ }^{3}$ Dube P., Meyer S., Marnewick J. L. Antimicrobial and antioxidant activities of different solvent extracts from fermented and green honeybush (Cyclopia intermedia) plant material. South African Journal of Botany. 2017. 110. pp. 184-193.

${ }^{4}$ Sentkowska A., Pyrzynska K. Investigation of antioxidant interaction between Green tea polyphenols and acetaminophen using isobolographic analysis. Journal of Pharmaceutical and Biomedical Analysis. 2018. 15910. pp. 393-397.

${ }^{5}$ Steenkamp V., Fernandes A.C., van Rensburg C.E.J., Jäger A.K. Antioxidant scavenging potential of South African export herbal teas. South African Journal of Botany. 2004. 70 (4). pp. 660-663.

${ }^{6}$ Fai-Chu Wong, Jianbo Xiao, Shaoyun Wang, Kah-Yaw Ee, Tsun-Thai Chai. Advances on the antioxidant peptides from edible plant sources. Trends in Food Science \& Technology. 2020. 99. pp. 44-57. 
the other hand, when using vegetable raw materials, there are difficulties in ensuring the constant and predictable quality characteristics ${ }^{7,8}$ of alcoholic beverages.

To date, the antioxidant properties of the prescription components and their combinations have not yet been well studied. Some studies require a mechanism for the influence of prescription components ${ }^{9}$ on the level of toxicity of alcoholic beverages. Some components are potentially capable of increasing chronic ethanol toxicity.

The wide range and variety of alcoholic beverages is coupled with the ability to mix alcohol with many ingredients. Due to the different proportions of water-alcohol infusions of vegetable raw materials in the process of blending leads to new flavors that are completely different from each other, as well as their different beneficial properties.

But among all the useful properties, the main thing will be to change the redox reactions ${ }^{10},{ }^{11}$. Redox reactions affect the ratio of energy to support homeostasis. Homeostasis - relativity of dynamic constancy of composition and properties of internal environment and stability of basic physiological functions of an organism. This ensures the vital activity of any organism. The magnitude of this rate depends on the ratio and concentration of oxidized and reduced substances in the body, including substances coming from food and beverages, so one of the main factors in the regulation of redox reactions is the redox potential.

In the production of cocktails in restaurants, one of the possibilities of influencing the antioxidant properties of the product is the extraction of vegetable raw materials into alcoholic raw materials. This can improve organoleptic performance and the benefits of alcoholic cocktails.

${ }^{7}$ Dietrich I., Kuzmin O., Mikhailenko V. Comprehensive evaluation of the hot sweet soufflé dessert quality. Ukrainian Journal of Food Science. 2017. 5 (1). pp. 92-102.

${ }^{8}$ Kuzmin O., Levkun K., Riznyk A. Qualimetric assessment of diets. Ukrainian Food Journal. 2017. 6 (1). pp. 46-60.

${ }^{9}$ Frolova N., Ukrainets A., Sylka I., Nemirich A., Kuzmin O. Separation of terpenes from lemon essential oil by selective fractionation under a vacuum. EasternEuropean Journal of Enterprise Technologies. 2019. 2/11 (98). pp. 32-36.

${ }^{10}$ Gerolis L.G.L., Lameiras F.S., Krambrock K., Neves M.J. Effect of gamma radiation on antioxidant capacity of green tea, yerba mate, and chamomile tea as evaluated by different methods. Radiation Physics and Chemistry. 2017. 130. pp. 177-185.

${ }^{11}$ Gullón B., Eibes G., Moreira M.T., Herrera R., Gullón P. Yerba mate waste: A sustainable resource of antioxidant compounds. Industrial Crops and Products. 2018. 113. pp. 398-405. 
Due to the extraction of vegetable raw materials into alcoholcontaining raw materials, the enrichment of nutrients is obtained, which leads to an increase in the antioxidant properties of the solution.

These circumstances determine the relevance of the topic of scientific work, which is the development of water-alcohol infusions of vegetable raw materials in the technology of alcoholic beverages in restaurants. Creating low-toxicity alcoholic beverages through the introduction of herbal infusions with antioxidant properties allows restaurant establishments to create new products. This distinguishes them from competitors, creating a favorable image of an institution that cares about protecting consumers from the negative effects of alcohol.

The purpose of the work is to develop the scientific bases of antioxidant activity of water-alcohol infusions from vegetable raw materials and to identify the most promising plants as sources of natural antioxidants in the creation of alcoholic beverages in restaurants.

When achieving this goal, it is necessary to solve the following problems:

- to substantiate the prospect of using water-alcohol infusions from vegetable raw materials in the production of alcoholic beverages;

- to establish the value of the restorative capacity of water-alcohol infusions from vegetable raw materials;

- to conduct an organoleptic evaluation of water-alcohol infusions and to determine their prospects in alcoholic beverage technology;

- identify the most promising sources of natural antioxidants for use in alcoholic beverage technology;

- identify the best modifications of alcoholic beverages;

- to develop the prescription composition of alcoholic beverages.

Object of study: characteristics and quality indicators of wateralcohol infusions from vegetable raw materials: organoleptic characteristics (color, smell, taste); physicochemical indicators (hydrogen index - $\mathrm{pH}$ level, redox potential).

Subject of study: vodka with a volume fraction of ethyl alcohol $40 \%$ (control); vegetable raw materials - tea products; water-alcohol infusions from vegetable raw materials; cognac.

Research methods: redoxmetry - determination of antioxidant capacity of water-alcohol infusions of vegetable raw materials; $\mathrm{pH}$ metric; methods of determining organoleptic parameters.

Research methodology. The vegetable raw material was ground to $3 \times 3 \mathrm{~mm}$, placed a $4 \mathrm{~g}$ sample in glass vials, filled with $100 \mathrm{ml}$ alcoholcontaining solvent with $40 \%$ vol. The vials were closed with lids for 
10 days with stirring. The infusions were filtered and studies were conducted to determine the hydrogen index, which was measured on a $\mathrm{pH}$ meter in the $\mathrm{pH}$ level mode with a combined glass electrode. The redox potential was measured in the potential measurement mode with the combined redoxmetric platinum electrode.

The scientific novelty is:

- identification of groups of water-alcoholic infusions for the production of alcoholic beverages by antioxidant activity: infusions with low activity (from 0 to $100 \mathrm{mV}$ ) - 0 samples; infusions with average activity (from 100 to $200 \mathrm{mV}$ ) - 12 samples; infusions with high activity (from $200 \mathrm{mV}$ ) - 1 sample;

- the minimum theoretically expected value of redox potential $\left(\mathrm{RP}_{\min }\right)$ for water-alcohol infusions has been determined, which has a value from $283.8 \mathrm{mV}$ (infusion of yellow tea) to $465.3 \mathrm{mV}$ (infusion of hibiscus tea), and the actual measured of redox potential $\left(\mathrm{RP}_{\mathrm{act}}\right)$ - from $92.5 \mathrm{mV}$ (infusion of yellow tea) up to $228 \mathrm{mV}$ (infusion of hibiscus tea);

- the minimum value of the restorative ability (recovery energy $\mathrm{RE}$ ), which is equal to $-123.2 \mathrm{mV}$ and is characteristic for the honeybush infusion, and the largest value of $237.3 \mathrm{mV}$ is the wateralcohol infusion from the hibiscus tea;

- found that the $\mathrm{pH}$ level for water-alcohol infusions has a value from 3,245 (infusion of hibiscus tea) to 6,27 (infusion of yellow tea), that is, the infusions have reactions from acidic to neutral;

- establishment of the most promising samples of water-alcohol infusions, which have received high organoleptic characteristics and can be recommended in the technology of alcoholic beverages - the infusion of hibiscus tea and red tea -9.66 points.

Testing of research results. The main provisions and results of the experimental work were tested during the tasting of new developments at the Department of Technology of Restaurant and Ayurvedic Products of the National University of Food Technologies.

The socio-economic importance of the results obtained is the creation of semi-finished products - water-alcohol infusions of vegetable raw materials for alcoholic beverages with improved consumer properties.

\section{Characterization of the technological process of alcohol production}

Water-alcohol infusion is a semi-finished product of liqueur-vodka production, which is prepared by infusion of vegetable raw materials 
(aromatic and non-aromatic) in aqueous-alcoholic solution with a strength of $40 \%$ to $90 \%$, according to the technological instruction and the technological regulations with the observance of state sanitary rules and regulations.

Water-alcohol infusions are obtained by extraction with water-alcohol liquid of dried vegetable raw materials. In the process of extraction, the phenomenon of diffusion based on equalization of concentrations between the solvent and the solution of substances contained in the plant cell is used. This equalization of concentrations is expressed in the gradual mutual penetration of two substances bordering each other, and is caused by the chaotic motion of molecules, their kinetic energy.

The degree of extraction of soluble substances depends on the degree of grinding of raw materials; the ratio of raw materials and water-alcohol mixture; the concentration of alcohol in the aqueous-alcohol mixture; duration of infusion; numbers of raw material bay; mixing frequencies; temperature.

The simplest method of extraction is double infusion (maceration) at normal temperature, which consists of the following operations: raw material acceptance and weighing; sorting of raw materials and disposal of waste; waste weighing; grinding of raw materials; preparation of water-alcohol mixture of the required strength; loading of raw materials into a full container; pouring raw materials with a water-alcohol mixture; infusion of raw materials with a water-alcohol mixture with daily stirring for 5-14 days, depending on the type of raw materials; draining and pumping the infusion of the first drain into storage compartments and measuring the volume of infusion received; the second raw material feed with an aqueous-alcoholic mixture; re-infusion of raw materials with water-alcohol mixture with daily stirring for 5-10 days; draining, pumping and measuring the volume of the infusion of the first and second drains; mixing of infusions of the first and second drains; unloading of spent raw materials from an insulated container; evaporation of the alcohol remaining in the raw material.

Due to the infusion of tea products in the aqueous-alcoholic environment is extracted tannins substances, caffeine, vitamins, organic acids, essential oils, minerals, which lead to an increase in antioxidant properties and increase the time of sale of finished products.

\section{Classification of tea products}

Tea products include a group of foodstuffs including tea with additives, tea drink, instant tea, instant tea with additives, soluble tea 
drink, liquid concentrate of tea, liquid concentrate of tea with additives, liquid concentrate of tea drink, cold tea, and mate, hibiscus tea, rooibos, honeybush, catuaba.

Tea with additives is a food product containing at least $50 \%$ by weight of tea and other components.

Tea drink is a food product made from vegetable raw materials with a possible addition of tea in an amount of not more than $50 \%$ by weight and other components.

Instant tea is a dry food product soluble in water at the temperature specified in the manufacturer's instructions and containing at least $1.0 \mathrm{~g}$ of dry tea extract per $1 \mathrm{dm} 3$ infusion and containing no other components. Instant Tea with Supplements is a dry food product soluble in water at the temperature specified in the manufacturer's instructions and containing at least $1.0 \mathrm{~g}$ of dry tea extract per $1 \mathrm{dm}^{3}$ infusion and containing other components.

Instant tea drink is a dry food product soluble in water at the temperature specified in the manufacturer's instructions, with a possible content of dry tea extract of less than $1.0 \mathrm{~g}$ per $1 \mathrm{dm}^{3}$ infusion and a total content of dry tea extract and dry vegetable extract of not less than $1.0 \mathrm{~g}$ on $1 \mathrm{dm}^{3}$ infusion. The presence of other food components is allowed.

Liquid tea concentrate is a liquid food product soluble in water containing at least $1.0 \mathrm{~g}$ of dry tea extract per $1.0 \mathrm{dm}^{3}$ infusion and containing no other components. Liquid tea concentrate with additives is a liquid food product soluble in water containing at least $1.0 \mathrm{~g}$ of dry tea extract per $1 \mathrm{dm}^{3}$ of infusion and containing other components.

Liquid tea beverage concentrate is a liquid food product soluble in water, with a possible dry tea extract content of less than $1.0 \mathrm{~g}$ per $1 \mathrm{dm}^{3}$ infusion and a total dry tea extract content and dry vegetable extract of at least $1.0 \mathrm{~g}$ per $1 \mathrm{dm}^{3}$ infusion. The presence of other food components is allowed.

Cold tea is a liquid food product containing a dry tea extract and / or a dry vegetable extract in a total concentration of at least $1.0 \mathrm{~g}$ per $1 \mathrm{dm}^{3}$, ready for consumption. The presence of other food components is allowed. 


\section{Characteristics of the raw material used in the studies}

Black tea ${ }^{12}$ is a type of tea that is obtained by completely or almost completely oxidizing the leaf of the tea bush.

Yellow tea is a rare variety of high quality Chinese tea. Yellow tea is generally similar to green tea, but has some differences in production technology, namely the slow drying stage. This technological technique gives the yellow tea a special flavor, for which it is appreciated.

Red tea is the most fermented tea that is called in China for its infusion color. It is characterized by burgundy, amber and chestnut shades, rich aroma and a tart taste.

White tea is a low-oxidized type of tea. White tea has an extremely delicate aroma, which very easily absorbs the surrounding scents. That is why tea collectors are forbidden from eating onions, garlic, and spices, otherwise they can ruin the original flavor of the tea.

Green Tea ${ }^{13,14}$ - the kind of tea that is achieved through the processing of tea leaves: wilting + partial drying + twisting + drying. The main task in the manufacture of green tea - to preserve its biologically active natural substances contained in the tea leaf. That is why the process of making this kind of tea is not "aggressive" and is subordinated to the goal of preserving the nutrients in the leaf. Green tea contains a large amount of caffeine and with prolonged brewing it can start to get bitter. Properly brewed green tea contains a unique blend of vitamins, trace elements and other nutrients (such as plant proteins).

Mate $^{15,16,17}$ (Paraguay Tea) is a dry leaf of an evergreen shrub of Paraguayan holly. Mate is known for its supposedly rich healing

12 Gulua L., Nikolaishvili L., Jgenti M., Turmanidze T., Dzneladze G. Polyphenol content, anti-lipase and antioxidant activity of teas made in Georgia. Annals of Agrarian Science. 2018. 16 (3). pp. 357-361.

${ }^{13}$ Gerolis L.G.L., Lameiras F.S., Krambrock K., Neves M.J. Effect of gamma radiation on antioxidant capacity of green tea, yerba mate, and chamomile tea as evaluated by different methods. Radiation Physics and Chemistry. 2017. 130. pp. 177-185.

${ }^{14}$ Sentkowska A., Pyrzynska K. Investigation of antioxidant interaction between Green tea polyphenols and acetaminophen using isobolographic analysis. Journal of Pharmaceutical and Biomedical Analysis. 2018. 15910. pp. 393-397.

${ }^{15}$ Gerolis L.G.L., Lameiras F.S., Krambrock K., Neves M.J. Effect of gamma radiation on antioxidant capacity of green tea, yerba mate, and chamomile tea as evaluated by different methods. Radiation Physics and Chemistry. 2017. 130. pp. 177-185. 
properties and contains a lot of caffeine. The drink should be bitter. Has a specific aroma. The taste is reminiscent of strong green tea.

Hibiscus ${ }^{18}$ tea is a sweet-sour-flavored drink of bright red color, made from dried Rosella flowers. Hot tea is drunk as a cool drink in the heat.

Rooibos $^{19}$ - a drink obtained by brewing dried crushed leaves and shoots of Aspalathus linearis.

Honeybush $^{20}$ - a drink ("herbal tea"), which is made from some species of South African plants belonging to the genus Cyclopia.

Catuaba $^{21}$ - made for the infusions of the bark of a number of trees, originally from Brazil. The bark infusion is used in traditional Brazilian medicine as a stimulant and central nervous system stimulant.

\section{Materials and methods}

The main tool that provides the vital activity of any organism and regulates the ratio of the amount of energy to maintain homeostasis (the relative dynamic constancy of the composition and properties of the internal environment and the stability of the basic physiological functions of the body) and spent on the regeneration of cells of the body, is a change in the rate of reactions of organisms. This rate depends on the

${ }^{16}$ Gullón B., Eibes G., Moreira M.T., Herrera R., Gullón P. Yerba mate waste: A sustainable resource of antioxidant compounds. Industrial Crops and Products. 2018. 113. pp. 398-405.

17 Pâmela T. A. N. Kungel, Vanesa G. Correa, Rúbia C. G. Corrêa, Rosely Aparecida Peralta, Rosane M. Peralta. Antioxidant and antimicrobial activities of a purified polysaccharide from yerba mate (Ilex paraguariensis). International Journal of Biological Macromolecules. 2018. 11415. pp. 1161-1167.

${ }^{18}$ Nasir A. Siddiqui, Hanan M. Al-Yousef, Tawfeq A. Alhowiriny, Perwez Alam, Rehab H. Abdallah. Concurrent analysis of bioactive triterpenes oleanolic acid and $\beta$ amyrin in antioxidant active fractions of Hibiscus calyphyllus, Hibiscus deflersii and Hibiscus micranthus grown in Saudi Arabia by applying validated HPTLC method. Saudi Pharmaceutical Journal. 2018. 26, pp. 266-273.

19 Joubert E., de Beer D. Phenolic content and antioxidant activity of rooibos food ingredient extracts. Journal of Food Composition and Analysis. 2012. 27 (1). pp. $45-51$.

${ }^{20}$ J. D. van der Merwe, D. de Beer, S. Swanevelder, E. Joubert, W. C. A. Gelderblom. Dietary exposure to honeybush (Cyclopia) polyphenol-enriched extracts altered redox status and expression of oxidative stress and antioxidant defense-related genes in rat liver. South African Journal of Botany. 2017. 110. pp. 230-239.

21 Jean Paul Kamdem, Elekofehinti Olusola Olalekan, Waseem Hassan, Ige Joseph Kade, João Batista Teixeira Rocha. Trichilia catigua (Catuaba) bark extract exerts neuroprotection against oxidative stress induced by different neurotoxic agents in rat hippocampal slices. Industrial Crops and Products. 2013. 50. pp. 625-632. 
concentration and the ratio of oxidized and reduced forms of substances in the body, so one of the most significant factors regulating the parameters of redox reactions is the redox potential.

The redox potential quantitatively determines the activity of ions in redox reactions and characterizes the deviation from the ionic balance of free electrons, whose change in concentration leads to a change in the electron charge of the liquid medium. In addition, the redox potential characterizes the biological activity of the liquid medium, which affects biological systems and allows the energy of these processes to be evaluated. The positive value of the redox potential is due to the decrease in the activity of the electrons in the solution, which indicates the oxidizing ability, the redox potential with the negative value is determined by the increase in the activity of the electrons and indicates the restorative capacity.

At redoxmetry (measurement on a platinum electrode relative to a chlorine silver reference electrode) the redox potential of the internal environment of a healthy human body is less than zero $(-100 \ldots-200 \mathrm{mV})$. In this case, the redox potential of drinking water from the urban water supply network, depending on the location of the water intake, the time of year, the water treatment system (except for electrochemical activation) is always greater than zero $(+100 \ldots+400 \mathrm{mV})$.

These differences of redox potential of the internal environment of the human body and drinking water mean that the activity of electrons in the internal environment of the body is much higher than the activity of electrons in drinking water. In the body there is a necessary change in the redox potential of drinking water due to the consumption of electrical energy of cell membranes, is energy of the highest level, energy, which is actually the end product of the biochemical chain of nutrient transformation. The amount of energy consumed by the body to achieve the biological compatibility of water is proportional to its amount and the difference of the redox potential of water and the internal environment of the body.

In addition to drinking water, a person consumes water and wateralcohol mixtures, food, the redox potential of which is positive. When such products get into the body tissues, electrons are removed from cells and tissues, which are $80-90 \%$ composed of water. As a result, the biological structures of the organism (cell membranes, cell organoids, nucleic acids, etc.) are subjected to oxidative destruction, the organism wears out, ages, and vital organs lose their function. 
When aqueous solutions (food) with a negative redox potential close to the values of the redox potential of the internal environment of the human body enter the body, the electrical energy of the cell membranes is not spent on the correction of the activity of the electrons of aqueous solutions (food), so the products are immediately assimilated because they have biological compatibility under this parameter.

If aqueous solutions (food) have a redox potential more negative than the redox potential of the internal environment of the body, then they feed it with this energy, which is used by cells as an energy reserve of antioxidant protection of the body against the adverse effects of the external environment.

We can conclude that in order for the human body to optimally use in the metabolic processes aqueous solutions (food), the values of redox potential must correspond to the values of redox potential of the internal environment of the organism, or have more negative values.

The quantitative characteristic of the acidity or alkalinity of the aqueous medium is the hydrogen index $(\mathrm{pH})$, which is determined by the activity of hydrogen ions $\left(\mathrm{a}_{\mathrm{H}}^{+}\right)$or, otherwise, by the ratio of the concentration of hydroxonium ions $\mathrm{H}_{3} \mathrm{O}^{+}$and hydroxyl $\mathrm{OH}^{-}$, whereas the acidity and alkalinity characterize the quantitative content in the aqueous medium capable of neutralizing with alkali and acid.

The $\mathrm{pH}$ of aqueous solutions is in the range from 0 to 14 . If the water content of $\mathrm{H}_{3} \mathrm{O}^{+}$is reduced compared to $\mathrm{OH}^{-}$ions, then the water will have an alkaline reaction $(\mathrm{pH}>7)$, with an increased content of $\mathrm{H}_{3} \mathrm{O}^{+}$ions - acidic $\left(\mathrm{pH}<7\right.$ ), with equal concentrations of $\mathrm{H}_{3} \mathrm{O}^{+}$ions and $\mathrm{OH}^{-}$- neutral $(\mathrm{pH}=7)$.

There is a relationship between the redox potential and the $\mathrm{pH}$ level, which is expressed by the fact that when the $\mathrm{pH}$ of the water changes by 1 unit. by the addition of sodium hydroxide or hydrochloric acid, the redox potential changes accordingly by about $59 \mathrm{mV}$ - increases with decreasing $\mathrm{pH}$ and decreases with increasing it.

To evaluate the $\mathrm{pH}$ and redox potential (RP) of solutions, the following formula is valid:

$$
\mathrm{RP}_{\min }=660-60 \cdot \mathrm{pH}, \mathrm{mV}
$$

where $\mathrm{RP}_{\min }$ - the minimum theoretically expected value of the redox potential; $\mathrm{pH}$ - the hydrogen index of the test solution. 
The acquired values of $\mathrm{RP}_{\min }$ are compared with actual measurements of $\mathrm{RP}_{\mathrm{act}}$ of solution. The shift of the redox potential towards the recovery values, as the recovery energy $(\mathrm{RE})$, is determined by the formula:

$$
\mathrm{RE}=\mathrm{RP}_{\min }-\mathrm{RP}_{\mathrm{act}}, \mathrm{mV}
$$

where $\mathrm{RE}$ - the energy of recovery (restorative capacity); $\mathrm{RP}_{\mathrm{act}}-$ the actual measured redox potential of the solution.

It can be concluded that the use of water-alcohol infusions from tea products with specified values of redox potential, will allow their use as semi-finished products for the production of alcoholic beverages, which are able to change the speed and direction of redox processes in the body, regulate biological and slow down negative processes in the human body. The result will be a product with protective restorative properties.

\section{Results and discussions}

In the first stage, water-alcohol infusions were created according to the following scheme. Teas (black, red, yellow, white, green) and tea products (mate, hibiscus, rooibos, honeybush, catuaba) were placed in a container for infusion and spent the first pour in the volume of wateralcohol mixture and infused for 5 days at room temperature, periodically stirring the raw materials. During the first bay infusions of the 1 st shower were received. A second feed of the raw material was carried out with an aqueous-alcoholic mixture, followed by infusion for 5 days. In the process, infusions of the second shower were received. The obtained infusions of the 1st and 2nd drains were mixed and received wateralcohol infusions. After all stages of preparation of water-alcohol infusions, their studies were performed according to organoleptic and physicochemical parameters (Table 1. and Fig. 1-7).

The control sample of the aqueous-alcoholic solution at $\mathrm{t}=20^{\circ} \mathrm{C}$ has a value of $\mathrm{pH}=5.63, \mathrm{RP}_{\min }=322.2 \mathrm{mV}, \mathrm{RP}_{\mathrm{act}}=181.0 \mathrm{mV}, \mathrm{RE}=141.2 \mathrm{mV}$. Organoleptic control properties with an overall score of 9.50 points.

The sample of infusion of black tea at $\mathrm{t}=20^{\circ} \mathrm{C}$ has a value of $\mathrm{pH}=5.48, \quad \mathrm{RP}_{\min }=331.2 \mathrm{mV}, \quad \mathrm{RP}_{\mathrm{act}}=152.5 \mathrm{mV}, \quad \mathrm{RE}=178.7 \mathrm{mV}$. Organoleptic control properties with an overall score of 9.62 points. 
Table 1

Characteristics of water-alcohol infusions of tea and tea products

\begin{tabular}{|c|c|c|c|c|c|}
\hline Raw materials & $\begin{array}{c}\text { Organoleptic } \\
\text { values, scores }\end{array}$ & $\begin{array}{c}\text { Hydrogen } \\
\text { index, } \mathbf{p H} \\
\mathbf{u n i t s}\end{array}$ & $\begin{array}{c}\mathbf{R P}_{\mathbf{m i n}}, \\
\mathbf{m V}\end{array}$ & $\begin{array}{c}\mathbf{R P}_{\text {act }}, \\
\mathbf{m V}\end{array}$ & $\begin{array}{c}\mathbf{R E} \\
\mathbf{m V}\end{array}$ \\
\hline $\begin{array}{c}\text { Water-alcohol } \\
\text { mixture }\end{array}$ & 9,50 & 5,630 & 322,2 & 181,0 & 141,2 \\
\hline $\begin{array}{c}\text { Infusion of black } \\
\text { tea }\end{array}$ & 9,62 & 5,480 & 331,2 & 152,5 & 178,7 \\
\hline $\begin{array}{c}\text { Infusion of yellow } \\
\text { tea }\end{array}$ & 9,63 & 6,270 & 283,8 & 92,5 & 191,3 \\
\hline Infusion of red tea & 9,66 & 5,550 & 327,0 & 146,5 & 180,5 \\
\hline $\begin{array}{c}\text { Infusion of white } \\
\text { tea }\end{array}$ & 9,64 & 6,230 & 286,2 & 97,0 & 189,2 \\
\hline $\begin{array}{c}\text { Infusion of green } \\
\text { tea }\end{array}$ & 9,63 & 6,160 & 290,4 & 105,0 & 185,4 \\
\hline Infusion with mate & 9,63 & 5,735 & 315,9 & 131,1 & 184,8 \\
\hline $\begin{array}{c}\text { Infusion of } \\
\text { hibiscus }\end{array}$ & 9,66 & 3,245 & 465,3 & 228,0 & 237,3 \\
\hline $\begin{array}{c}\text { Infusion of } \\
\text { rooibos green }\end{array}$ & 9,60 & 5,500 & 330,3 & 176,0 & 154,3 \\
\hline $\begin{array}{c}\text { Infusion of } \\
\text { rooibos }\end{array}$ & 9,63 & 5,410 & 335,4 & 209,5 & 125,9 \\
\hline $\begin{array}{c}\text { Infusion of } \\
\text { honeybush green }\end{array}$ & 9,58 & 5,440 & 333,9 & 185,5 & 148,4 \\
\hline $\begin{array}{c}\text { Infusion of } \\
\text { honeybush }\end{array}$ & 9,56 & 5,210 & 347,7 & 224,5 & 123,2 \\
\hline $\begin{array}{c}\text { Infusion of } \\
\text { catuaba }\end{array}$ & 9,65 & 5,420 & 335,1 & 168,5 & 166,6 \\
\hline
\end{tabular}

The minimum theoretically expected value of the redox potential $\left(\mathrm{RP}_{\min }\right)$ for water-alcohol infusions ranges from $283.8 \mathrm{mV}$ (infusion of yellow tea), to $465.3 \mathrm{mV}$ (infusion of hibiscus tea), the actual measured redox potential of the solution $\left(\mathrm{RP}_{\mathrm{act}}\right)$ - from $92.5 \mathrm{mV}$ (infusion of yellow tea) to $228 \mathrm{mV}$ (hibiscus tea infusion).

The minimum recovery energy (RE) $-123.2 \mathrm{mV}$ and is characteristic of the honeybush infusion, and the largest value of $237.3 \mathrm{mV}$ is wateralcohol infusion from the hibiscus tea.

The $\mathrm{pH}$ level for water-alcohol infusions ranges from 3.245 (infusion of hibiscus tea) to 6.27 (infusion of yellow tea), ie infusions have reactions from acidic to neutral. 


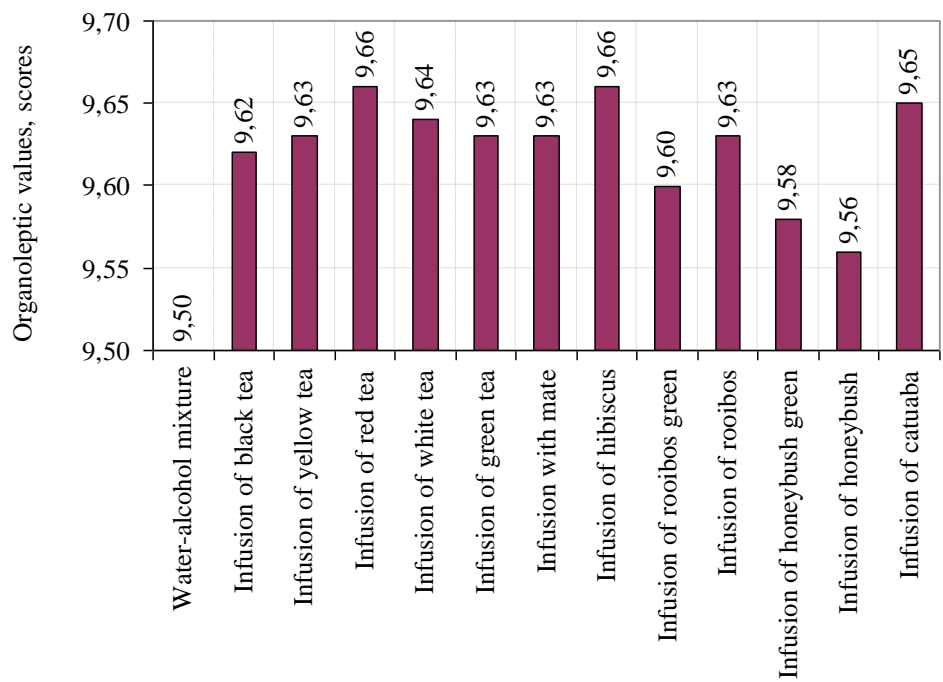

Fig. 1. Organoleptic characteristics of water-alcohol infusions

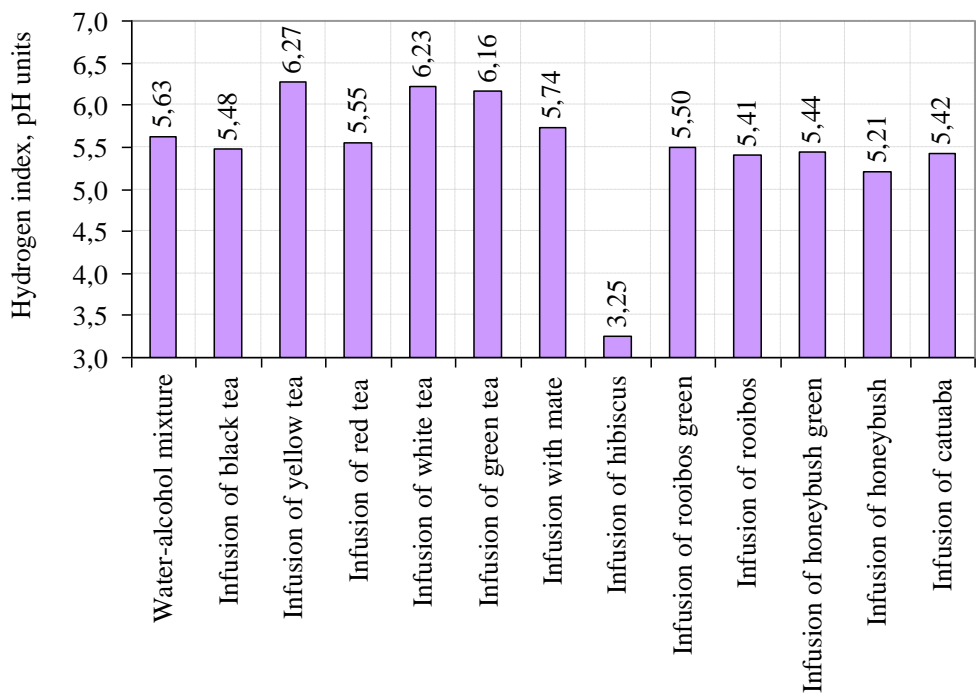

Fig. 2. pH level of water-alcohol infusions of vegetable raw materials 


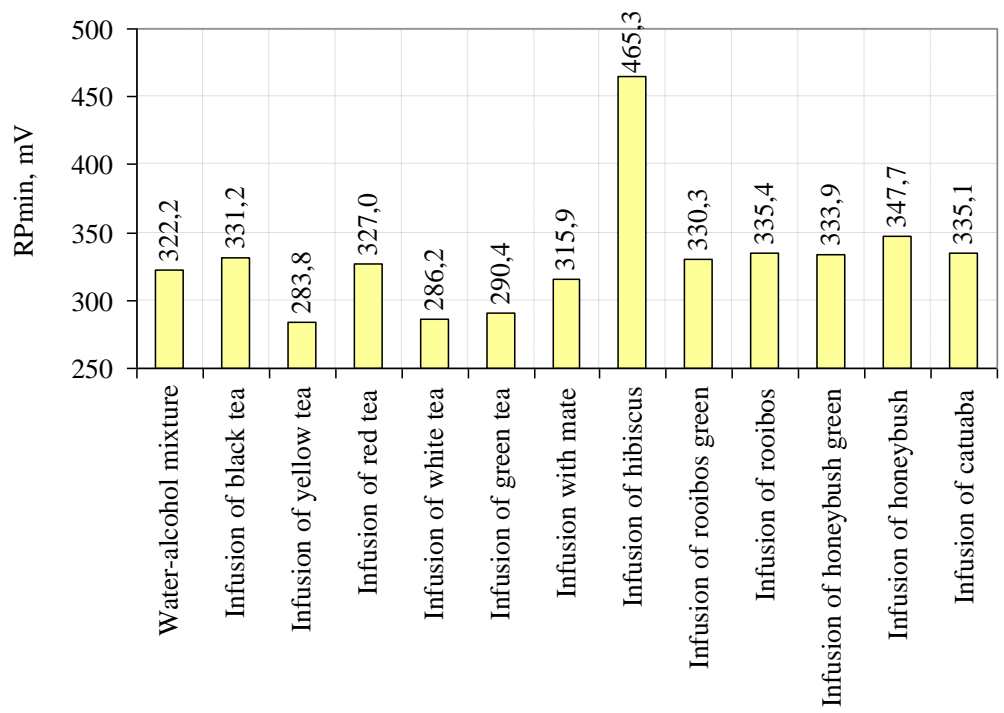

Fig. 3. $\mathbf{R P}_{\min }$ of water-alcohol infusions of vegetable raw materials

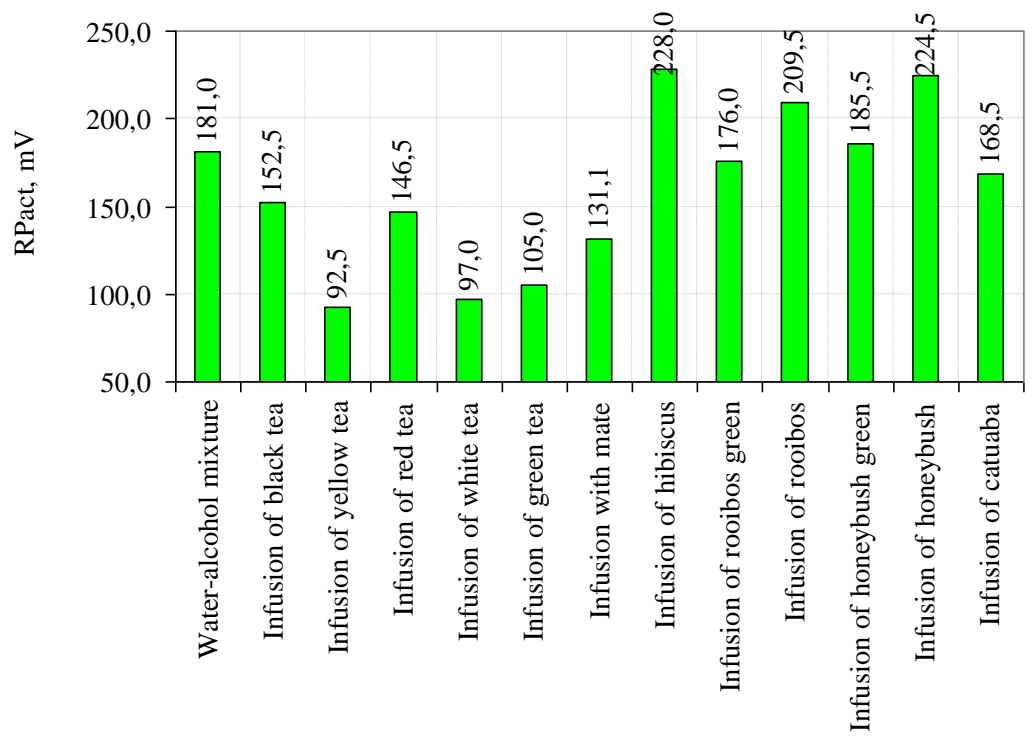

Fig. 4. $R P_{\text {act }}$ of water-alcohol infusions of vegetable raw materials 


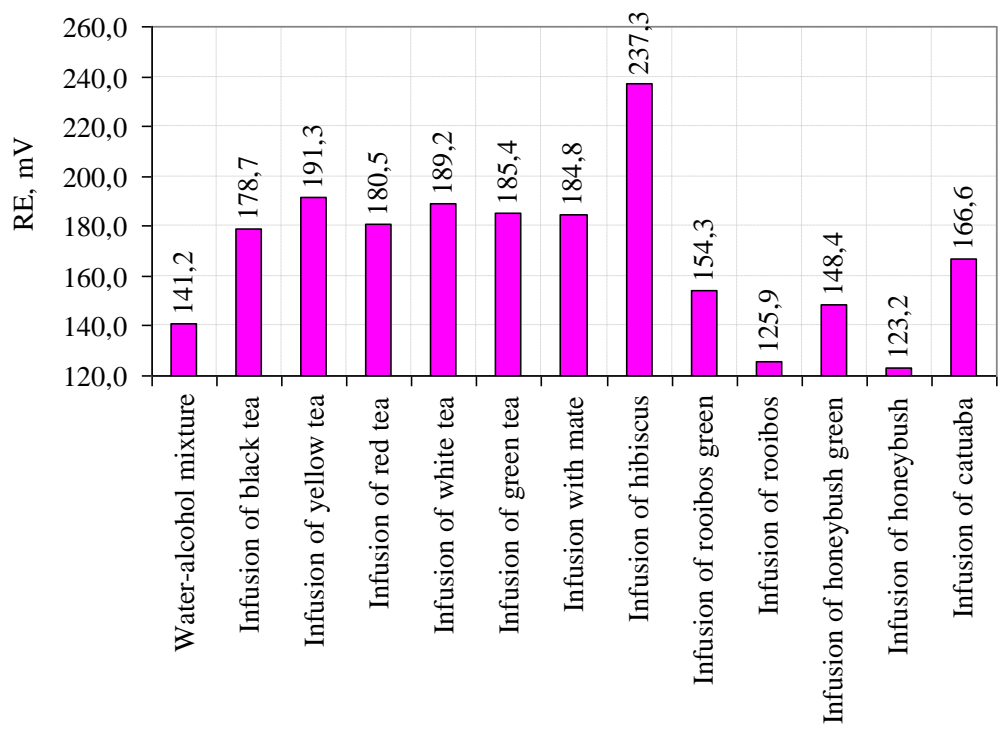

Fig. 5. RE of water-alcohol infusions of vegetable raw materials

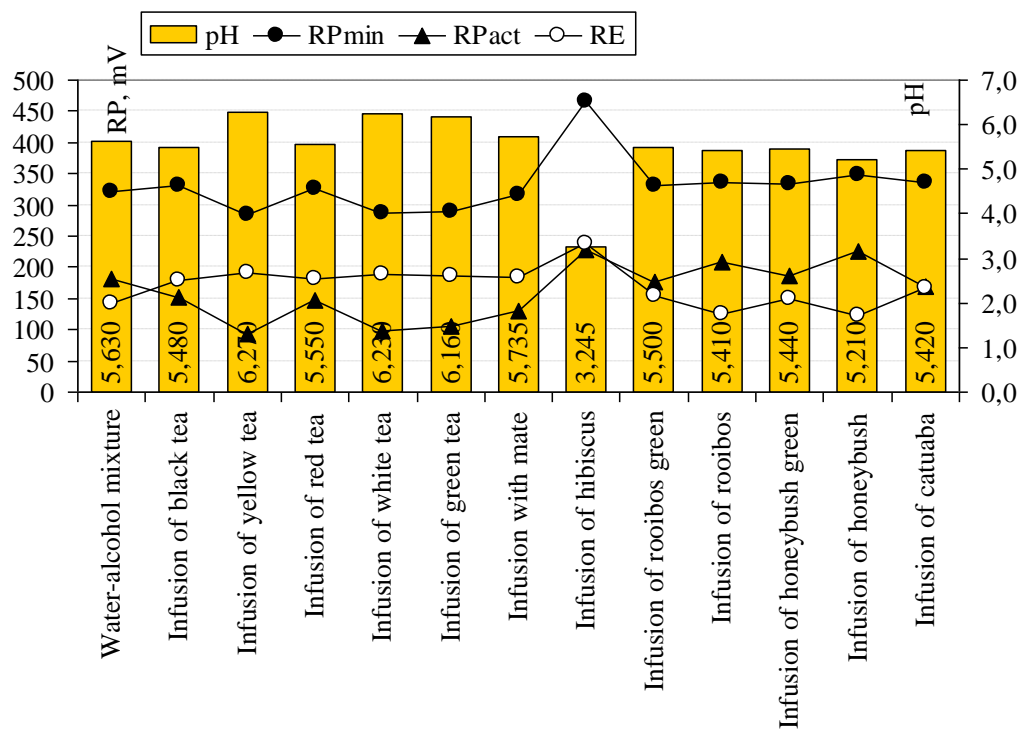

Fig. 6. Physicochemical characteristics of water-alcohol infusions 


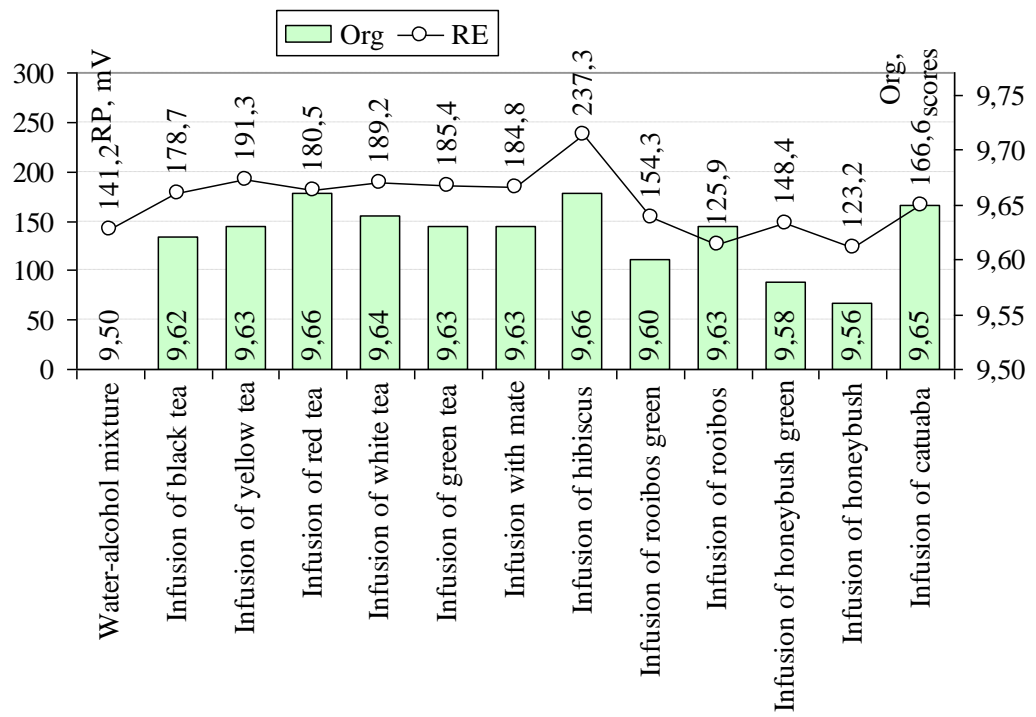

Fig. 7. Physicochemical and organoleptic characteristics of water-alcohol infusions

The most promising samples of water-alcohol infusions, which have high organoleptic characteristics and can be recommended in the technology of alcoholic cocktails - infusions of hibiscus tea and red tea 9.66 points.

The groups of water-alcohol infusions for the production of alcoholic cocktails by antioxidant activity were determined: infusions with low activity (from 0 to $100 \mathrm{mV}$ ) - 0 samples; infusions with average activity (from 100 to $200 \mathrm{mV}$ ) - 12 samples; infusions with high activity (from $200 \mathrm{mV}$ ) - 1 sample.

For blending of alcoholic beverage was added (Table 2): wateralcohol infusion of tea products $-38,49 \%$, cognac $-7,54 \%$, vanillin $1: 10-0,01 \%$, sugar syrup $65,8 \%-53,08 \%$, citric acid $-0.28 \%$, "color" $-0.6 \%$, rectified ethyl alcohol and water - based on the strength of $20 \%$ (Fig. 8). 
Table 2

Ingredients content

\begin{tabular}{|c|c|c|c|c|c|}
\hline $\begin{array}{c}\text { Water-alcohol } \\
\text { infusion of tea } \\
\text { products, \% }\end{array}$ & Cognac, \% & $\begin{array}{c}\text { Vanillin } \\
\mathbf{1 : 1 0 , \%}\end{array}$ & $\begin{array}{c}\text { Sugar } \\
\text { syrup } \\
\mathbf{6 5 , 8 \%} \%\end{array}$ & $\begin{array}{c}\text { Citric } \\
\text { acid, \% }\end{array}$ & Color\% \\
\hline 38,49 & 7,54 & 0,01 & 53,08 & 0,28 & 0,6 \\
\hline
\end{tabular}

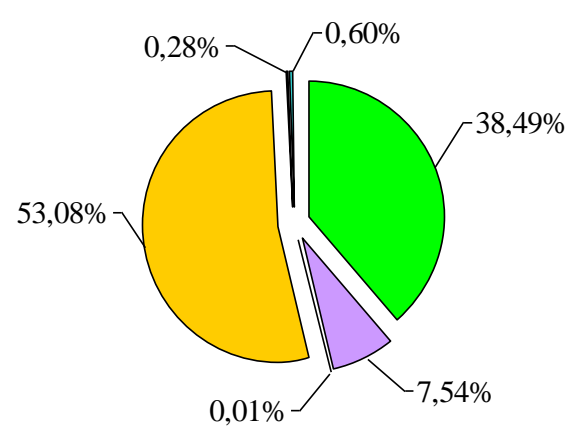

$\square$ Water-alcohol infusion of tea products, $\%$

$\square$ Cognac, $\%$

Vanillin 1:10,\%

$\square$ Sugar syrup $65,8 \%, \%$

Citric acid, \%

Color, $\%$

Fig. 8. Blending of alcoholic beverage

\section{CONCLUSIONS}

The established perspective of ways of forming consumer properties and expanding the range of alcoholic cocktails is the use of different infusions of tea products. Such substances or their combinations are intended to improve the organoleptic properties of beverages, to give them stable therapeutic and prophylactic properties - to promote the promotion of human health (antioxidant, membrane-stabilizing effect, enhancing redox reactions and enhancing the normalization of the action hormonal status of the body).

\section{SUMMARY}

Creating low-toxicity alcoholic beverages allows a manufacturing company to market new products. It is these products that distinguish the range of manufacturers from the range of competitors, creating a favorable image of the company, which cares about protecting consumers from the negative effects of alcohol on the basis of the latest technologies. 
Thus, the study of redox reactions occurring during the manufacture of water-alcohol infusions is important to ensure their stability and safety for consumption.

\section{REFERENCES}

1. Breiter T., Laue C. Kressel G., Gröll S., Hahn A. Bioavailability and antioxidant potential of rooibos flavonoids in humans following the consumption of different rooibos formulations. Food Chemistry. 2011. 128 (215). pp. 338-347. DOI 10.1016/j.foodchem.2011.03.029.

2. Dietrich I., Kuzmin O., Mikhailenko V. Comprehensive evaluation of the hot sweet soufflé dessert quality. Ukrainian Journal of Food Science. 2017. 5 (1). pp. 92-102. DOI 10.24263/2310-1008-2017-5-1-12.

3. Dube P., Meyer S., Marnewick J.L. Antimicrobial and antioxidant activities of different solvent extracts from fermented and green honeybush (Cyclopia intermedia) plant material. South African Journal of Botany. 2017. 110. pp. 184-193. DOI 10.1016/j.sajb.2016.10.010.

4. Fai-Chu Wong, Jianbo Xiao, Shaoyun Wang, Kah-Yaw Ee, TsunThai Chai. Advances on the antioxidant peptides from edible plant sources. Trends in Food Science \& Technology. 2020. 99. pp. 44-57. DOI 10.1016/j.tifs.2020.02.012.

5. Frolova N., Ukrainets A., Sylka I., Nemirich A., Kuzmin O. Separation of terpenes from lemon essential oil by selective fractionation under a vacuum. Eastern-European Journal of Enterprise Technologies. 2019. 2/11 (98). pp. 32-36. DOI 10.15587/1729-4061.2019.160220.

6. Gerolis L.G.L., Lameiras F.S., Krambrock K., Neves M.J. Effect of gamma radiation on antioxidant capacity of green tea, yerba mate, and chamomile tea as evaluated by different methods. Radiation Physics and Chemistry. 2017. 130. pp. 177-185. DOI 10.1016/j.radphyschem.2016.08.017.

7. Gullón B., Eibes G., Moreira M.T., Herrera R., Gullón P. Yerba mate waste: A sustainable resource of antioxidant compounds. Industrial Crops and Products. 2018. 113. pp. 398-405. DOI 10.1016/j.indcrop.2018.01.064.

8. Gulua L., Nikolaishvili L., Jgenti M., Turmanidze T., Dzneladze G. Polyphenol content, anti-lipase and antioxidant activity of teas made in Georgia. Annals of Agrarian Science. 2018. 16 (3). pp. 357-361. DOI 10.1016/j.aasci.2018.06.006. 
9. Jean Paul Kamdem, Elekofehinti Olusola Olalekan, Waseem Hassan, Ige Joseph Kade, João Batista Teixeira Rocha. Trichilia catigua (Catuaba) bark extract exerts neuroprotection against oxidative stress induced by different neurotoxic agents in rat hippocampal slices. Industrial Crops and Products. 2013. 50. pp. 625-632. DOI 10.1016/j.indcrop.2013.07.033.

10. J. D. van der Merwe, D. de Beer, S. Swanevelder, E. Joubert, W. C. A. Gelderblom. Dietary exposure to honeybush (Cyclopia) polyphenol-enriched extracts altered redox status and expression of oxidative stress and antioxidant defense-related genes in rat liver. South African Journal of Botany. 2017. 110. pp. 230-239. DOI 10.1016/j.sajb.2016.08.004.

11. Joubert E., de Beer D. Phenolic content and antioxidant activity of rooibos food ingredient extracts. Journal of Food Composition and Analysis. 2012. 27 (1). pp. 45-51. DOI 10.1016/j.jfca.2012.03.011.

12. Kuzmin O., Kovalchuk Y., Velychko V., Romanchenko N. Improvement technologies of aqueous-alcoholic infusions for the production of syrups. Ukrainian Journal of Food Science. 2016.4 (2). pp. 258-275. DOI 10.24263/2310-1008-2016-4-2-8.

13. Kuzmin O., Levkun K., Riznyk A. Qualimetric assessment of diets. Ukrainian Food Journal. 2017. 6 (1). pp. 46-60. DOI 10.24263/2304-974X-2017-6-1-7

14. Nasir A. Siddiqui, Hanan M. Al-Yousef, Tawfeq A. Alhowiriny, Perwez Alam, Rehab H. Abdallah. Concurrent analysis of bioactive triterpenes oleanolic acid and $\beta$-amyrin in antioxidant active fractions of Hibiscus calyphyllus, Hibiscus deflersii and Hibiscus micranthus grown in Saudi Arabia by applying validated HPTLC method. Saudi Pharmaceutical Journal. 2018. 26, pp. 266-273. DOI 10.1016/j.jsps.2017.11.013

15. Pâmela T. A. N. Kungel, Vanesa G. Correa, Rúbia C. G. Corrêa, Rosely Aparecida Peralta, Rosane M. Peralta. Antioxidant and antimicrobial activities of a purified polysaccharide from yerba mate (Ilex paraguariensis). International Journal of Biological Macromolecules. $2018.211415 . \quad$ pp. 1161-1167. DOI 10.1016/j.ijbiomac.2018.04.020

16. Sentkowska A., Pyrzynska K. Investigation of antioxidant interaction between Green tea polyphenols and acetaminophen using 
isobolographic analysis. Journal of Pharmaceutical and Biomedical Analysis. 2018. 15910. pp. 393-397. DOI 10.1016/j.jpba.2018.07.029.

17. Steenkamp V., Fernandes A.C., van Rensburg C.E.J., Jäger A.K. Antioxidant scavenging potential of South African export herbal teas. South African Journal of Botany. 2004. 70 (4). pp. 660-663. DOI 10.1016/S0254-6299(15)30207-6.

\section{Information about authors:}

Kuzmin O. V.,

Candidate of Technical Sciences, Associate Professor at the Department of Technology of Restaurant and Ayurvedic Products National University of Food Technologies 68, Volodymyrska Str., Kyiv, 01601, Ukraine

Rudyi V. V.,

Student of the National University of Food Technologies 68, Volodymyrska Str., Kyiv, 01601, Ukraine 